\title{
Review
}

\section{Key stages in mammary gland development Involution: apoptosis and tissue remodelling that convert the mammary gland from milk factory to a quiescent organ}

\author{
Christine J Watson
}

Department of Pathology, University of Cambridge, Tennis Court Road, Cambridge CB2 1QP, UK

Corresponding author: Christine JWatson, cjw53@mole.bio.cam.ac.uk

Published: 10 April 2006

This article is online at http://breast-cancer-research.com/content/8/2/203

(c) 2006 BioMed Central Ltd
Breast Cancer Research 2006, 8:203 (doi:10.1186/bcr1401)

insufficient apoptosis can result in cancer. Thus, the study of apoptosis in the mammary gland is important for understanding both the normal biology of post-lactational regression and the events leading to breast tumourigenesis.

The physiology and genetics of apoptosis are easily studied in the mouse mammary gland. Most of the secretory epithelium is removed within 6 days of weaning in the mouse and the gland is then remodelled to a pre-pregnant state in preparation for a subsequent pregnancy. The study of apoptosis in the mouse mammary gland has been facilitated by using a forced weaning protocol in which the suckling pups are removed when they are about 10 days old, at the peak of lactation and prior to a natural wean. This precipitates a synchronous involution and allows the study of the molecular mechanism(s) involved and the morphological features associated with these molecular events. Forced involution and glucocorticoid administration studies revealed two phases of involution: a first phase that lasts for 48 hours and is reversible; and a second phase that initiates a remodelling programme that returns the gland to a prepregnant state [5]. Thus, if pups are returned to the mother within 48 hours, apoptosis is halted and lactation recommences. Using teat-sealing, it was demonstrated that the first phase is regulated by local factors within the individual gland and not circulating hormones $[6,7]$ while the second phase is dependent on circulating factors and can be halted by the administration of glucocorticoid $[5,8]$, possibly through maintenance of tight junctions [9]. The remodelling phase is also dependent on the activity of specific matrix metalloproteases (MMPs) whose function is blocked in the first phase by expression of tissue inhibitors of metalloproteases (TIMPs) [10]. Therefore, in any study of involution, it is important to consider the timing of events and to put these in

Akt = serine/threonine kinase Akt; DR $=$ death receptor; IKK = IKB kinase; Jak = Janus kinase; LIF = leukaemia inhibitory factor; MMP $=$ matrix metalloprotease; NF = nuclear factor; pAkt = phosphorylated Akt; PKB = protein kinase B; Stat = signal transducer and activator of transcription; $\mathrm{TGF}=$ transforming growth factor; TIMP $=$ tissue inhibitor of metalloproteases; TNF $=$ tumour necrosis factor; TUNEL $=$ terminal deoxynucleotidyl transferase nick end labelling; TWEAK = tumor necrosis factor-like weak inducer of apoptosis. 
the context of the two distinct phases of the involution process.

In recent years, sophisticated genetic approaches have allowed us to identify the essential components of the two phases of involution. It is possible to abolish first phase apoptosis or second phase remodelling, or to shorten the first phase by accelerating the rate of apoptosis. More and more genes are being implicated in apoptosis regulation during involution. The majority of these are likely to be downstream components of the signalling pathways that are essential regulators of involution, and thus may have a minor role to play in the overall process. In this review, therefore, I will summarise primarily genetic studies that have shed light on the events and signalling pathways that are critically involved in initiating and controlling apoptosis. It is clear that the overall process is highly complex, so only the principal events will be discussed here. A more extensive review can be found in [11].

\section{The first phase of involution: an apoptosis-only event}

Several signalling pathways have been implicated in first phase involution. The use of genetically modified mice, and particularly the advent of tissue-specific gene deletion, has revealed a number of factors that either promote, or delay, involution and apoptosis. These include members of the Bcl-2 family: deletion of the anti-apoptotic Bcl-x gene accelerates apoptosis while loss of the pro-apoptotic Bax protein delays involution [12,13]. Many of these factors make a minor contribution to the involution process, however, either because of redundancy or because they are not essential components of the primary regulatory pathways. One of these primary pathways is the Janus kinase (Jak)/signal transducer and activator of transcription (Stat) pathway, which is activated in response to cytokines and growth factors, resulting in the phosphorylation and dimerisation of specific Stat molecules that translocate to the nucleus and activate transcription of their target genes. While Stat5 is important for lobuloalvoelar development [14], Stat3 is critical for the initiation of apoptosis and involution [15,16]. In the absence of Stat3, apoptosis is dramatically repressed and the first phase is abolished. It is now known that the cytokine leukaemia inhibitory factor (LIF) is the activator of Stat3 in vivo $[17,18]$ and a number of downstream target genes of Stat3 have been identified $[15,19]$. Recently, two of these targets, IGFBP-5 and c/ebp $\delta$, have been shown to be important in the apoptotic response in mammary gland $[20,21]$ and the diminished involution in e/ebp $\delta$-deficient mammary glands lends further support to the primary function of the LIF/Stat3 axis. Interestingly, apoptosis can be suppressed in the presence of constitutively active serine/ threonine kinase Akt/protein kinase B (Akt/PKB) [22], suggesting that phosphorylated ( $p$ )Akt provides an overriding survival signal. This is further supported by a recent study showing that Stat3 induces the expression of negative regulatory subunits of $\mathrm{PI}(3)$ kinase, resulting in diminished levels of pAkt [23]. This suggests that pAkt is a molecular sentinel for survival/death signals in mammary epithelium. This is clearly not the whole story, as other pathways feed into Akt and will affect the outcome of Stat3 signalling. One such pathway is the nuclear factor (NF)- $\kappa B / \mathrm{l}_{\kappa} \mathrm{B}$ kinase (IKK)/death receptor (DR) pathway, which has recently been shown to regulate apoptosis and involution in mammary gland, probably through transcriptional regulation of the DR ligands tumour necrosis factor (TNF) $\alpha$ and tumor necrosis factor-like weak inducer of apoptosis (TWEAK) (FO Baxter, PJ Came, K Abell, B Kedjouar, M Huth, K Rajewsky, M Pasparakis, CJ Watson, submitted).

Apoptosis in mammary gland has been studied since 1986. Most previous work focussed on apoptosis at days 2 and 3 of involution, however, as this is when the most terminal deoxynucleotidyl transferase nick end labelling (TUNEL) positive cells were seen. However, it is now clear that the initial apoptotic signals are much earlier in the involution process. LIF transcription is induced 30 -fold within 12 hours of forced weaning [17] and microarray data from 2 independent studies $[24,25]$ reveals a cluster of genes that are transcriptionally upregulated between lactation and 12 hours involution and subsequently decline by 24 hours. Some of these genes encode DR ligands such as TNF, TWEAK and FasL. Furthermore, expression of transforming growth factor (TGF) $\beta 3$ is induced within 8 hours of forced weaning, and triggers phosphorylation of Stat3 [26]. Genetic evidence from TGF $\beta 3$ deficient mice further suggests that this ligand is important for initiating involution.

Morphologically, the first phase is marked by the detachment of cells from the alveolar structures and shedding into the lumen. It is known that some cells are shed during lactation. However, the accumulation of shed cells is not apparent before 9 hours of forced weaning, whereupon there is a dramatic increase in shed, caspase-3 positive cells by 12 hours (CJ Watson, unpublished data). This suggests that there is an initial apoptotic signal within a few hours of forced weaning that elicits the death programme in a considerable number of cells. Interestingly, while some alveoli contain 5 to 10 shed cells, others have none. This may indicate that individual alveoli have different concentrations of factors in the accumulated milk, or that apoptotic cells induce apoptosis in their neighbours, perhaps by secreting a proapoptotic cytokine. It is worth noting that active (cleaved) caspase-3, a definitive marker of apoptosis, is observed only in the shed cells at 12 and 24 hours involution and not in the alveolar wall until 72 hours (CJ Watson, unpublished data). Thus, it is possible that cells are detached from their neighbours and expelled into the lumen where they die from anoikis and a lack of survival signals. However, it is more likely that the apoptosis programme is initiated before the cells detach but that cleavage of caspase-3 does not occur until the cell has been removed from the epithelial layer. 

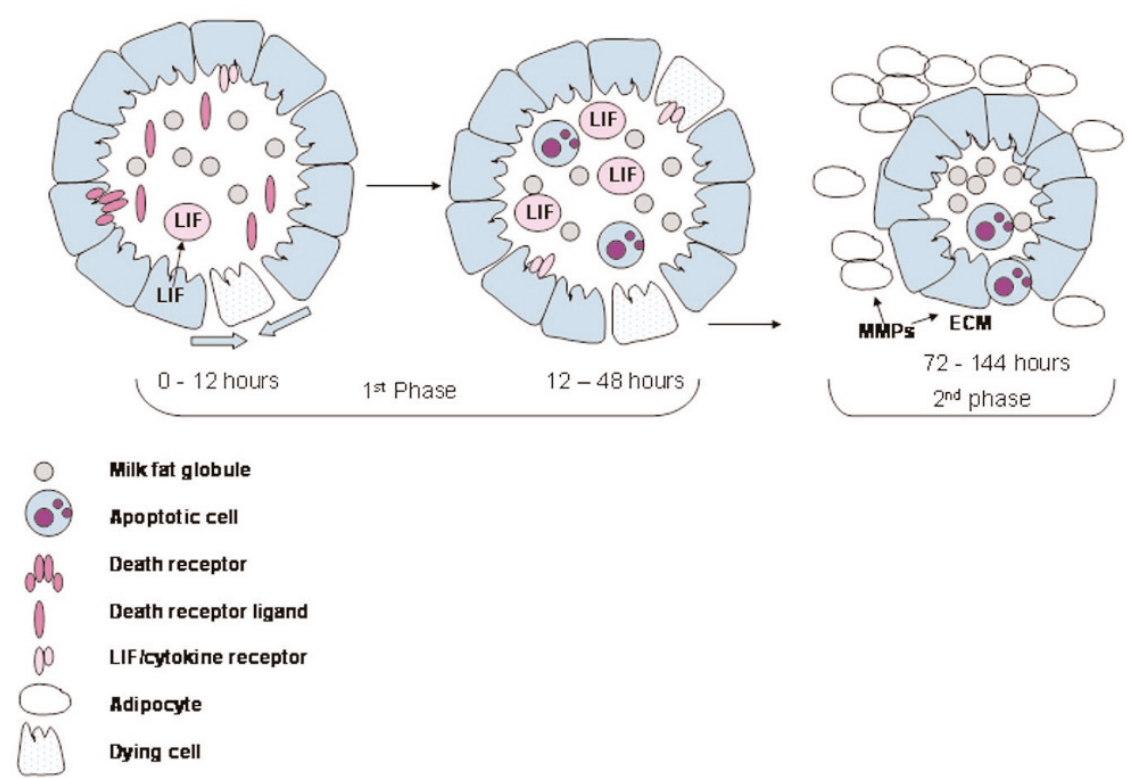

Signalling events in involution. Milk stasis induces the expression of leukaemia inhibitory factor (LIF) and transforming growth factor (TGF) 33 within 12 hours of forced weaning. These, in turn, phosphorylate and activate the transcription factor Stat3. This results in the induction of apoptosis and shedding of dying cells into the alveolar lumen. Neighbouring cells migrate to close the gap and maintain the integrity of the alveolar structure. Concurrently with these events, members of the death receptor ligand family and their receptors are transcriptionally upregulated and this induces apoptosis through activation of caspase 8. Downstream targets of these pathways are then induced and ensure the transition to the second phase. Following this reversible first phase, matrix metalloproteases (MMP) begin to break down the ECM surrounding each alveolus, resulting in detachment induced apoptosis and collapse of the alveoli. Remodelling is then completed by re-differentiation of the adipoctyes which requires the action of plasmin and MMP3. Full involution returns the gland to a pre-pregnant state. ECM, extracellular matrix.

These data and observations can be combined to illuminate the initial events in involution (Figure 1). In response to withdrawal of the suckling stimulus, milk accumulates and this induces the expression of LIF, TGF 33 and DR ligands that in turn trigger the induction of apoptosis through the death receptor pathway and the Jak/Stat pathway. Downstream targets of this pathway are upregulated and these ensure the transition to the second phase. A delay of several hours is required for the expression of these ligands. This does not exclude the possibility that concentrations of cytokines and chemokines that are normally secreted in the milk may increase due to stasis and could also contribute to the earliest events.

\section{The second phase of involution: death and destruction}

The architecture of the gland is not changed during the first phase. Post 48 hours when the transition to the second phase occurs, however, the alveoli start to collapse and adipocytes begin to re-fill. Important regulators of these processes are MMPs and serine proteases that break down the extra-cellular matrix and activate plasminogen, respectively, resulting in a second wave of apoptosis and tissue remodelling [10]. The MMPs are primarily expressed by the stromal cells and MMP2, MMP3 and MMP9 are upregulated during involution, when their function is to remodel the matrix.
Removal of the matrix induces apoptosis of the epithelial cells [27] and thus the MMPs have a dual role as initiators of apoptosis and as remodellers of gland architecture. Thus, if MMPs are activated on cue, cells that have failed to respond to first phase apoptotic signals will still be induced to die by detachment-induced apoptosis. To maintain the reversibility of the first phase, it is critically important that MMPs are not activated until 72 hours. This is achieved by expression of the cognate inhibitors, TIMPs. TIMP3, an inhibitor of MMP2, appears to be particularly important as involution is accelerated in TIMP3-deficient mammary glands [28] and first phase reversibility is lost. Concomitant with the loss of the mammary epithelium through apoptosis, the surrounding adipocytes differentiate, a process requiring both plasmin and MMP3 $[5,29]$. In the absence of plasminogen, involution is delayed and this is accompanied by abnormal differentiation of adipocytes [30] in a process that requires kallikrein [31]. However, the role of adipogenesis and how it is regulated during remodelling is incompletely understood and much remains to be learned about this essential process.

Finally, phagocytosis is an important constituent of the remodelling process. This may involve both autophagy and phagocytosis by professional and non-professional phagocytes due to the large number of cells and debris that have to be removed [32]. Recently, it has been shown that the 
secreted glycoprotein milk fat globule epidermal growth factor (EGF) factor 8 (MFG-E8), which binds to apoptotic cells by recognizing phosphatidylserine, is essential for normal second phase involution and the clearance of milk fat globules [33]. Inflammatory mediators that are activated earlier in involution probably signal the influx of macrophages that are seen in increased numbers at day 4 involution [25]. This is balanced by anti-inflammatory mediators to prevent overt inflammation $[24,25]$. This balance appears to be skewed in the absence of Stat3, as mastitis and inflammatory cells are seen in Stat3 deficient mammary glands [15]. It is noteworthy that NF-KB is also involved in inflammatory responses and it is conceivable that these two signalling pathways not only moderate the death/survival balance but also the inflammatory response.

It is perhaps timely to re-appraise earlier data on apoptosis and involution in light of recent technological advances that have allowed more precise characterisation of the process. In particular, measuring the number of apoptotic cells may be misleading since it is not known how quickly these are removed and the rate of phagocytosis may differ between first and second phases, depending on the number of phagocytes present. It is worth noting that if DNA is hypercompacted or degraded by phagocytes, it will no longer be detectable by the TUNEL assay and so misleading results could be obtained.

\section{Conclusion}

Many pieces of the involution jigsaw are now in place. The core signalling programmes that regulate apoptosis are well understood. There are, however, details still to be completed. For example, the roles of specific components of the apoptotic machinery have not been comprehensively addressed. Although a number of caspases, both initiator and executioner, have been shown to be cleaved and activated during involution [34], nothing is known with regard to redundancy and kinetics. The morphology of apoptotic cells is different in the first and second phases, and it is reasonable to expect that the apoptotic mechanisms differ in these phases. Microarray data supports the notion that second phase apoptosis is most likely mediated by the classic mitochondrial pathway [24].

Future work will need to address a number of outstanding questions. What are the earliest signals? What is the

This article is part of a review series on Key stages in mammary gland development, edited by Charles Streuli.

Other articles in the series can be found online at http://breast-cancer-research.com/articles/ review-series.asp?series=bcr_keystages mechanism of the transition from reversible to irreversible phase? Which downstream components of the signalling pathways are the critical effectors? And how are the stem cells protected from apoptosis? These are challenging tasks and we are still some way from a detailed understanding of the involution process. The devil may well be in the detail.

\section{Competing interests}

The author declares that they have no competing interests.

\section{References}

1. Gräper L: Arch Zellforsch 1914, 12:373-394.

2. Kerr J, Wyllie A, Currie A: Apoptosis: a basic biological phenomenon with wide-ranging implications in tissue kinetics. $\mathrm{Br}$ J Cancer 1972, 26:239-257.

3. Danial NN, Korsmeyer SJ: Cell death: Critical control points. Cell 2004, 116:205-219.

4. Melino G, Knight RA, Nicotera P: How many ways to die? How many different models of cell death? Cell Death Diff 2005, 12: 1457-1462.

5. Lund LR, Romer J, Thomasset N, Solberg H, Pyke C, Bissell MJ, Danø K, Werb Z: Two distinct phases of apoptosis in mammary gland involution: proteinase-independent and dependant pathways. Development 1996, 122:181-193.

6. Marti A, Feng Z, Altermatt HJ, Jaggi R: Milk accumulation triggers apoptosis of mammary epithelial cells. Eur J Cell Biol 1997, 73:158-165.

7. Li M, Liu X, Robinson G, Bar-Peled U, Wagner KU, Young WS, Hennighausen L, Furth PA: Mammary-derived signals activate programmed cell death during the first stage of mammary gland involution. Proc Natl Acad Sci USA 1997, 94:3425-3430.

8. Feng Z, Marti A, Jehn B, Altermatt HJ, Chicaiza G, Jaggi R: Glucocorticoid and progesterone inhibit involution and programmed cell death in the mouse mammary gland. $J \mathrm{Cell} \mathrm{Biol}$ 131:1095-1103.

9. Zettl KS, Sjaastad MD, Riskin PM, Parry G, Machen TE, Firestone GL: Glucocorticoid-induced formation of tight junctions in mouse mammary epithelial cells in vitro. Proc Natl Acad Sci USA 1992, 89:9069-9073.

10. Green KA, Lund LR: ECM degrading proteases and tissue remodelling in the mammary gland. Bioessays 2005, 27:894903.

11. Green $\mathrm{KA}$, Streuli $\mathrm{CH}$ : Apoptosis regulation in the mammary gland. Cell Mol Life Sci 2004, 61:1867-1883.

12. Walton KD, Wagner KU, Rucker EB 3rd, Shillingford JM, Miyoshi $\mathrm{K}$, Hennighausen L: Conditional deletion of the bcl-x gene from mouse mammary epithelium results in accelerated apoptosis during involution but does not compromise cell function during lactation. Mech Dev 2001, 109:281-293.

13. Schorr K, Li, M, Bar-Peled, U, Lewis A, Heredia A, Lewis B, Knudson CM, Korsmeyer SJ, Jäger R, Weiher H, Furth PA: Gain of $\mathrm{Bcl}-2$ is more potent than bax loss in regulating mammary epithelial cell survival in vivo. Cancer Res 1999, 59:2541-2545.

14. Teglund S, McKay C, Schuetz E, van Deursen JM, Stravopodis D, Wang D, Brown M, Bodner S, Grosveld G, Ihle JN: Stat5a and Stat5b proteins have essential and nonessential, or redundant, roles in cytokine responses. Cell 1998, 93:841-850.

15. Chapman RS, Lourenco PC, Tonner E, Flint DJ, Selbert S, Takeda K, Akira S, Clarke AR, Watson CJ: Suppression of epithelial apoptosis and delayed mammary gland involution in mice with a conditional knockout of Stat3. Genes Dev 1999, 13: 2604-2616.

16. Humphreys RC, Bierie B, Zhao L, Raz, R, Levy D, Hennighausen $\mathrm{L}$ : Deletion of Stat3 blocks mammary gland involution and extends functional competence of the secretory epithelium in the absence of lactogenic stimuli. Endocrinology 2002, 143: 3641-3650.

17. Kritikou EA, Sharkey A, Abell K, Came PJ, Anderson E, Clarkson RWE, Watson CJ: A dual, non-redundant, role for LIF as a regulator of development and Stat3-mediated cell death in mammary gland. Development 2003, 130:3459-3468.

18. Schere-Levy C, Buggiano V, Quaglino A, Gattelli A, Cirio MC, Piazzon I, Vanzulli S, Kordon EC: Leukemia inhibitory factor 
induces apoptosis of the mammary epithelial cells and participates in mouse mammary gland involution. Exp Cell Res 2003, 282:35-47.

19. Clarkson RWE, Boland MP, Kritikou EA, Lee JM, Freeman TC, Tiffen PG, Watson CJ: The genes induced by Stat3 and Stat5 in mammary epithelial cells define the roles of these Stats in mammary gland development. Mol Endo 2006, 20:675-685.

20. Tonner E, Barber MC, Allan GJ, Beattie J, Webster J, Whitelaw $\mathrm{CB}$, Flint DJ: Insulin-like growth factor binding protein-5 (IGFBP-5) induces premature cell death in the mammary glands of transgenic mice. Development 2002, 129:4547-4557.

21. Thangaraju $M$, Rudelius $M$, Bierie B, Raffeld $M$, Sharan $S$, Hennighausen L, Huang AM, Sterneck E: C/EBPS is a crucial regulator of pro-apoptotic gene expression during mammary gland involution. Development 2005, 132:4675-4685.

22. Schwertfeger KL, Richert MM, Anderson SM: Mammary gland involution is delayed by activated Akt in transgenic mice. Mol Endo 2001, 15:867-881.

23. Abell K, Bilancio A, Clarkson RW, Tiffen PG, Altaparmakov Al, Burdon TG, Asano T, Vanhaesebroeck B, Watson CJ: Stat3induced apoptosis requires a molecular switch in $\mathrm{PI}(3) \mathrm{K}$ subunit composition. Nat Cell Bio/ 2005, 7:392-398.

24. Clarkson RW, Wayland MT, Lee J, Freeman T, Watson CJ: Gene expression profiling of mammary gland development reveals putative roles for death receptors and immune mediators in post-lactational regression. Breast Cancer Res 2004, 6:R92109.

25. Stein T, Morris JS, Davies CR, Weber-Hall SJ, Duffy MA, Heath VJ, Bell AK, Ferrier RK, Sandilands GP, Gusterson BA: Involution of the mouse mammary gland is associated with an immune cascade and an acute-phase response, involving LBP, CD14 and STAT3. Breast Cancer Res 2004, 6:R75-R91.

26. Nguyen AV, Pollard J: Transforming growth factor beta3 induces cell death during the first stage of mammary gland involution. Development 2000, 127:3107-3118.

27. Pullan S, Wilson J, Metcalfe A, Edwards GM, Goberdhan N, Tilly J, Hickman JA, Dive C, Streuli CH: Requirement of basement membrane for the suppression of programmed cell death in mammary epithelium. 1996, 109:631-642.

28. Fata JE, Leco KJ, Voura EB, Yu HY, Waterhouse P, Murphy G, Moorehead RA, Khokha R: Accelerated apoptosis in the Timp3-deficient mammary gland. J Clin Invest 2001, 108:831-841.

29. Alexander CM, Selvarajan S, Mudgett J, Werb Z: Stromelysin-1 regulates adipogenesis during mammary gland involution. $J$ Cell Biol 2001, 152:693-703.

30. Lund LR, Bjorn SF, Sternlicht MD, Nielsen BS, Solberg H, Usher PA, Osterby R, Christensen IJ, Stephens RW, Bugge TH, et al:: Lactational competence and involution of the mouse mammary gland require plasminogen. Development 2000, 127:4481-4492.

31. Selvarajan S, Lund LR, Takeuchi T, Craik CS, Werb Z: A plasma kallikrein-dependent plasminogen cascade required for adipocyte differentiation. 2001, 3:267-275.

32. Monks J, Rosner D, Geske FJ, Lehman L, Hanson L, Neville MC, Fadok VA: Epithelial cells as phagocytes: apoptotic epithelial cells are engulfed by mammary alveolar epithelial cells and repress inflammatory mediator release. Cell Death Differ 2005, 12:107-114.

33. Hanayama R, Nagata S: Impaired involution of mammary glands in the absence of milk fat globule EGF factor 8. Proc Natl Acad Sci U S A 2005, 102:16886-16891.

34. Marti A, Ritter PM, Jager R, Lazar H, Baltzer A, Schenkel J, Declercq W, Vandenabeele P, Jaggi R: Mouse mammary gland involution is associated with cytochrome c release and caspase activation. Mech Dev 104:89-98. 